\title{
Thermal Decomposition Kinetics of Poly(L-lactic acid) after Heat Treatment
}

\author{
Yan-Hua Cai ${ }^{*}$, Yun-Chen Xie, Ying-Tang and Li-Sha Zhao
}

\begin{abstract}
Chongqing Key Laboratory of Environmental Materials \& Remediation Technologies, Chongqing University of Arts and Sciences, Chongqing-402160, P.R. China
\end{abstract}

\begin{abstract}
Thermal decomposition behavior of Poly(L-lactic acid) (PLLA) and PLLA composites after different heat treatment were investigated using thermogravimetric analysis. Firstly, the thermal decomposition results of neat PLLA showed that the decomposition of PLLA was a first-order kinetic reaction, and thermal decomposition kinetics indicated that the heat treatment significantly affected activation energy of thermal decomposition of PLLA. The measurement results also exhibited that the onset decomposition temperature of PLLA treated below $115^{\circ} \mathrm{C}$ was lower than that of the pristine PLLA. Then, the effect of additive $\mathrm{CaCO}_{3}$ on the thermal decomposition behavior of PLLA was evaluated. The addition of $\mathrm{CaCO}_{3}$ could significantly improve the crystallization performance of $\mathrm{PLLA}$, but the $\mathrm{CaCO}_{3}$ did not change the decomposition trend of PLLA, and the thermal decomposition behavior of PLLA/CaCO $\mathrm{C}_{3}$ composites after isothermal heat treatment was similar to that of PLLA. However, the thermal decomposition activation energy of $\mathrm{PLLA} / \mathrm{CaCO}_{3}$ is lower than that of PLLA.
\end{abstract}

Keywords: Calcium carbonate, composites, crystallization, poly(L-lactic acid), thermal decomposition kinetics.

\section{INTRODUCTION}

Poly(L-lactic acid) (PLLA) is one of the most important biodegradable polymers [1]. There exist many literatures about PLLA and its composites based on PLLA [2, 3], and the addition of a functional additive can significantly improve the properties of PLLA. For example, Fan et al. [4] reported that $N, N^{\prime}$-bis(benzoyl)sebacic acid dihydrazide was synthesized and used as a nucleating agent for PLLA. The addition of $N, N^{\prime}$-bis(benzoyl)sebacic acid dihydrazide enhanced the crystallization rate of PLLA, and thermogravimetric analysis showed that the thermal stability of PLLA with $N, N^{\prime}$-bis(benzoyl)sebacic acid dihydrazide was enhanced, indicating that there were strong hydrogen bonds between $N, N^{\prime}$-bis(benzoyl)sebacic acid dihydrazide and PLLA matrix.

Thermal stability is key factor used to evaluate the application field of materials. Thus, the thermal stability of polymer and composites need to be investigated to meet application requirements. As to the PLLA and its composites, the decomposition behavior of PLLA and composites including decomposition process and kinetics had been reported in some papers. Yeng-Fong Shih et al. [5] prepared the PLA/banana fiber composites though melt blending technologies, the thermogravimetric analysis showed that the decomposition temperatures of PLLA reinforced by the banana fiber were smaller than those of the pristine PLA. However, the decomposition temperatures of

*Address correspondence to this author at the Chongqing Key Laboratory of Environmental Materials \& Remediation Technologies, Chongqing University of Arts and Sciences, Chongqing-402160, P.R. China;

Tel: +86-23-61162815; Fax: +86-23-61162815;

E-mail: caiyh651@aliyun.com
PLLA reinforced by the char yields of banana fiber were larger than those of pristine PLA. Meng et al. [6] reported that the addition of montmorrilonite considerably decreased the thermal decomposition rate and shifted the peak rate to a higher temperature compared to that of PLA composites with wood. Similarly, the incorporation of the montmorrilonite resulted in a significant improvement in the initial thermal stability of the both PLA and PLA/LLDPE nanocomposites [7].

There exists relevant literature to investigate the thermal decomposition kinetics of PLLA composites. However, in this article, we focus on the thermal decomposition behavior of PLLA and PLLA $/ \mathrm{CaCO}_{3}$ composites after heat treatment at different temperatures to illustrate the role of heating rate, heat treatment process and additive in decomposition behavior of PLLA. The related results can be used to help us further investigate the properties of PLLA to widen the application field of PLLA and composites.

\section{EXPERIMENTAL SECTION}

\subsection{Materials}

Poly(L-lactic acid) (2002D) from Nature Works LLC was purchased from the Kunshan Longyuan Plastic Company (JiangSu Province, China). The calcium carbonate $\left(\mathrm{CaCO}_{3}\right)$ of analytical grade was purchased from the Chengdu Kelong Chemical Reagents Company (Sichuan Province, China).

\subsection{Preparation of $\mathrm{PLLA} / \mathrm{CaCO}_{3}$ Composites}

Blending of PLLA and $\mathrm{CaCO}_{3}$ was performed on counter-rotating mixer from the Shanghai Kechuang Rubber Plastic Mechanical Equipment Co., Ltd., and the preparation 
process of PLLA $/ \mathrm{CaCO}_{3}$ composites is similar to that of our previous paper [8].

\subsection{Characterization}

The thermal decomposition behaviors of PLLA and PLLA $/ \mathrm{CaCO}_{3}$ composites were measured using Q500 thermogravimetric analysis (TGA) from TA InstrumentsWaters LLC with a different heating rate under air flow (60 $\mathrm{ml} / \mathrm{min}$ ) from room temperature to $600{ }^{\circ} \mathrm{C}$.

The isothermal crystallization behavior of PLLA and PLLA/ $\mathrm{CaCO}_{3}$ composites was evaluated by GJY-IIIoptical depolarizer from the Donghua University in China in the region from $100{ }^{\circ} \mathrm{C}$ to $120^{\circ} \mathrm{C}$.

\section{RESULTS AND DISCUSSION}

\subsection{Thermal Decomposition Behavior of PLLA}

Thermal decomposition of PLLA after heat treatment at different temperatures for $1 \mathrm{~h}$ is shown in Fig. (1). As shown in Fig. (1), there exists only one platform on the TGA curves, indicating that the decomposition of neat PLLA is a first-order kinetic reaction. At the same time, it is clear that the thermal decomposition temperature of PLLA went through the same heat treatment technology and increases with increasing of heating rate, resulting from thermal inertia. The larger heating rate makes the decomposition of PLLA not achievable at the set temperature, resulting in the decomposition occurring at a higher temperature. It is clear from Table 1 that the onset decomposition temperature of PLLA after heat treatment below $115^{\circ} \mathrm{C}$ is lower than that of the pristine PLLA, this is an interesting phenomenon, the possible reason is that there exists a substantial random
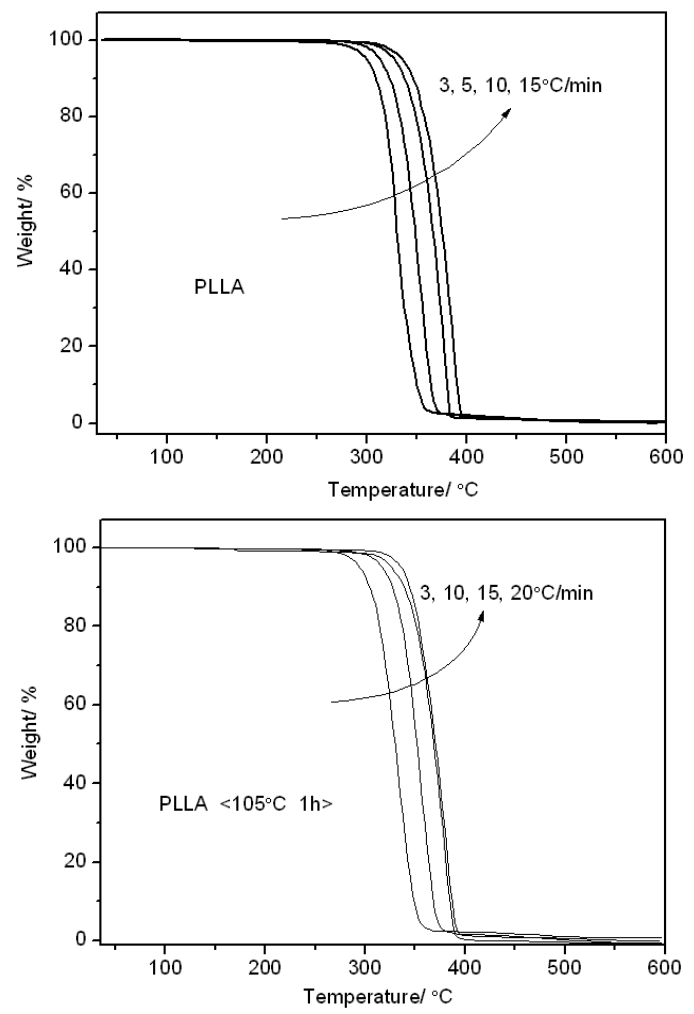

macromolecule segment in PLLA without heat treatment. This will impede the macromolecular segment active ability during the heating process. Meantime, the crystallization degree of PLLA could improve though heat treatment, but the crystallization ability of neat PLLA was very limited in the low temperature region, resulting in the easy formation of free molecular chain during the heat process. However, above $115^{\circ} \mathrm{C}$, the onset decomposition temperature of PLLA after heat treatment is higher than that of the pristine PLLA.

According to first-order kinetic reaction, thermal decomposition kinetics of PLLA can be described by the following Coats-Redfern equation [9]:

$$
\lg \left[-\frac{\ln (1-\alpha)}{T^{2}}\right]=\lg \left[\frac{A R}{\beta E_{a}}\left(1-\frac{2 R T}{E_{a}}\right)\right]-\frac{E_{a}}{2.303 R} \bullet \frac{1}{T}
$$

where, $\alpha$ is the mass loss rate, $\beta$ is the heating rate, $A$ is the frequency factor, $R$ is the gas constant, $E_{a}$ is activation energy. From this data we can easily obtain the temperature for the different mass loss rate at a different heating rate based on the TGA curves, and the relationship curves of $\lg [-$ $\left.\ln (1-\alpha) / \mathrm{T}^{2}\right]$ against $1 / \mathrm{T}$ are displayed in Fig. (2). As seen in Fig. (2), $\lg \left[-\ln (1-\alpha) / \mathrm{T}^{2}\right]$ and $1 / \mathrm{T}$ keep a favorable linear relationship, and the thermal decomposition kinetics parameters of PLLA after heat treatment are listed in Table 2. Apart from $3{ }^{\circ} \mathrm{C} / \mathrm{min}$, upon the same heating rate, $E_{a}$ of PLLA after heat treatment is higher than that of the pristine PLLA, indicating that the heat treatment significantly affects the $E_{a}$ of thermal decomposition of PLLA. In addition, it is observed that the heating rate can also slightly affect the $E_{a}$. The reason is that different heating rates make the decomposition of PLLA occurs at a different temperature.
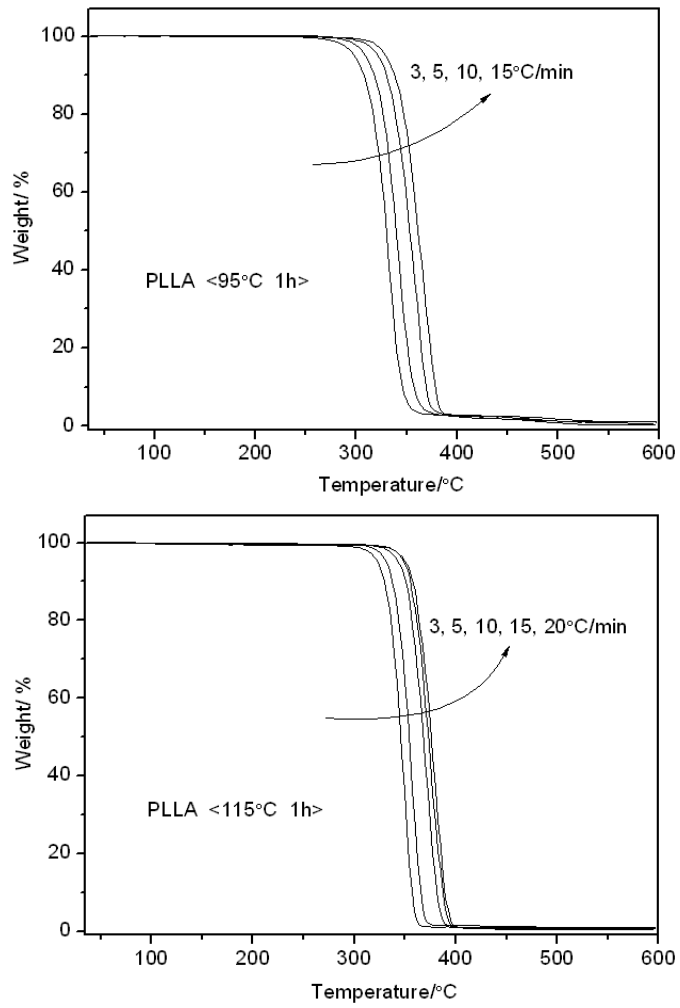

Fig. (1). Thermal decomposition of PLLA after heat treatment at different temperatures for $1 \mathrm{~h}$. 
Table 1. The onset decomposition temperatures of PLLA after heat treatment.

\begin{tabular}{|c|c|c|}
\hline Sample & $\boldsymbol{\beta}$ & Onset Temperature $/{ }^{\circ} \mathrm{C}$ \\
\hline \multirow{5}{*}{ PLLA } & 3 & 317.8 \\
\hline & 5 & 332.0 \\
\hline & 10 & 349.8 \\
\hline & 15 & 353.4 \\
\hline & 20 & 355.4 \\
\hline \multirow{4}{*}{$\operatorname{PLLA}\left(95^{\circ} \mathrm{C} 1 \mathrm{~h}\right)$} & 3 & 314.6 \\
\hline & 5 & 324.5 \\
\hline & 10 & 334.5 \\
\hline & 15 & 352.0 \\
\hline \multirow{4}{*}{$\operatorname{PLLA}\left(105^{\circ} \mathrm{C} 1 \mathrm{~h}\right)$} & 3 & 308.5 \\
\hline & 10 & 334.3 \\
\hline & 15 & 357.0 \\
\hline & 20 & 349.3 \\
\hline \multirow{5}{*}{$\operatorname{PLLA}\left(115^{\circ} \mathrm{C} 1 \mathrm{~h}\right)$} & 3 & 333.4 \\
\hline & 5 & 341.8 \\
\hline & 10 & 353.6 \\
\hline & 15 & 357.9 \\
\hline & 20 & 359.6 \\
\hline
\end{tabular}
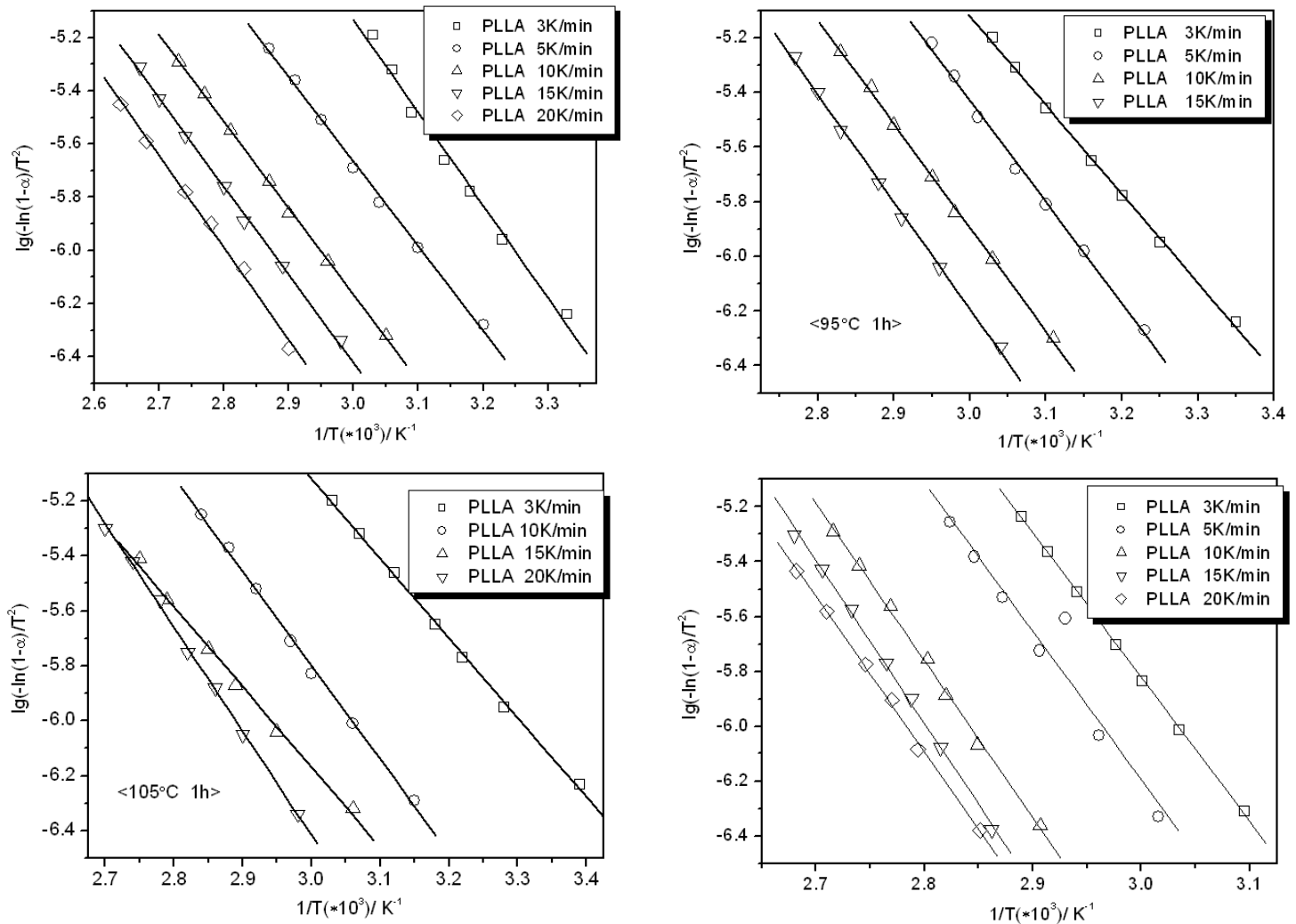

Fig. (2). Coats-Redfern curves of PLLA.
Table 2. Thermal decomposition kinetics parameters of PLLA.

\begin{tabular}{|c|c|c|}
\hline Sample & $\boldsymbol{\beta}$ & $\mathbf{E}_{\mathrm{a}} / \mathrm{KJ} / \mathbf{m o l}$ \\
\hline \multirow{5}{*}{ PLLA } & 3 & 66.778 \\
\hline & 5 & 61.007 \\
\hline & 10 & 62.215 \\
\hline & 15 & 63.431 \\
\hline & 20 & 66.187 \\
\hline \multirow{4}{*}{$\operatorname{PLLA}\left(95^{\circ} \mathrm{C} 1 \mathrm{~h}\right)$} & 3 & 62.347 \\
\hline & 5 & 71.144 \\
\hline & 10 & 75.113 \\
\hline & 15 & 72.740 \\
\hline \multirow{4}{*}{$\operatorname{PLLA}\left(105^{\circ} \mathrm{C} 1 \mathrm{~h}\right)$} & 3 & 55.473 \\
\hline & 10 & 65.388 \\
\hline & 15 & 55.964 \\
\hline & 20 & 72.547 \\
\hline \multirow{5}{*}{$\operatorname{PLLA}\left(115^{\circ} \mathrm{C} 1 \mathrm{~h}\right)$} & 3 & 100.779 \\
\hline & 5 & 103.432 \\
\hline & 10 & 109.742 \\
\hline & 15 & 113.673 \\
\hline & 20 & 108.418 \\
\hline
\end{tabular}

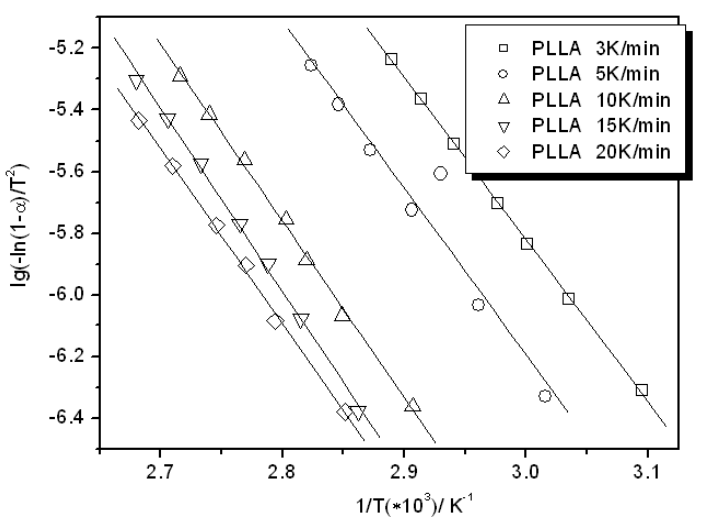




\subsection{Thermal Decomposition Behavior of PLLA/CaCO Composites}

Usually, the addition of an additive would more or less affect the physical and chemical performance of polymer. Thus, the effect of the additive on the thermal decomposition of the polymer matrix is also interesting for future research in enabling an understanding the role of additives. $\mathrm{CaCO}_{3}$ is a common commercial inorganic compound, and widely used to improve the mechanical properties of polymer materials [10-12]. Moreover, $\mathrm{CaCO}_{3}$ as a nucleating agent is used to improve the crystallization behavior of PLLA [13]. Similarly, the nucleating ability of $\mathrm{CaCO}_{3}$ for PLLA was firstly investigated before studying the thermal decomposition of PLLA $/ \mathrm{CaCO}_{3}$ composites. Fig. (3) shows the effect of $\mathrm{CaCO}_{3}$ and the crystallization temperature $\left(T_{c}\right)$ against the half time of overall PLLA crystallization $t_{1 / 2}$. The addition of $\mathrm{CaCO}_{3}$ makes the $t_{1 / 2}$ of PLLA decrease, indicating that the $\mathrm{CaCO}_{3}$ as a heterogeneous nucleating agent can promote the crystallization of PLLA. In addition, the $t_{1 / 2}$ of PLLA $/ 5 \% \mathrm{CaCO}_{3}$ composites firstly decreases, then increases with an increase of $T_{c}$. while $5 \% \mathrm{CaCO}_{3}$ makes the $t_{1 / 2}$ of PLLA decreases to the minimum value $352.52 \mathrm{~s}$ at $105^{\circ} \mathrm{C}$.

Similarly, the thermal decomposition behavior of PLLA $/ 5 \% \mathrm{CaCO}_{3}$ composites after heat treatment (isothermal crystallization) at different temperatures (See Fig. 4) is similar to that of PLLA. With increasing of heating rate, the onset decomposition temperature of PLLA $/ 5 \% \mathrm{CaCO}_{3}$ composites still increases. However, the addition of $\mathrm{CaCO}_{3}$ does not change the trend of decomposition curves of PLLA, resulting from the higher decomposition temperature of $\mathrm{CaCO}_{3}$.

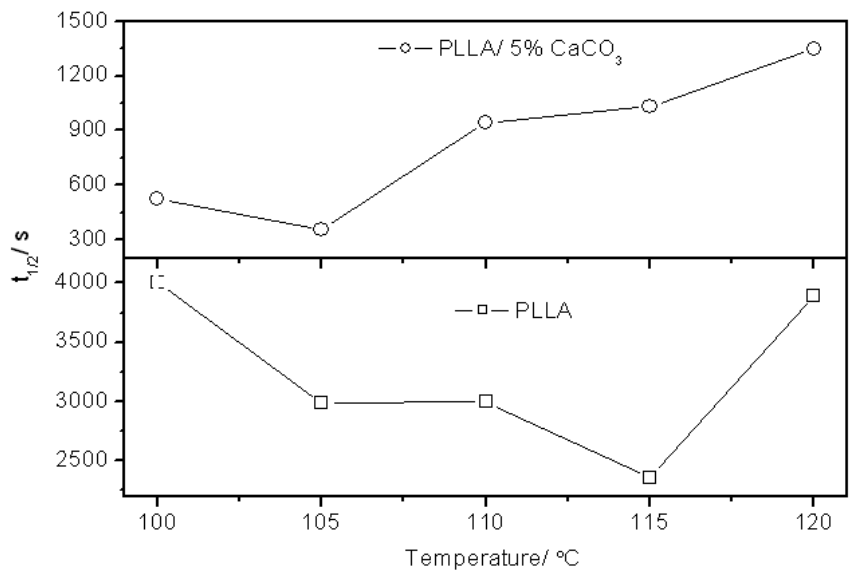

Fig. (3). The $t_{1 / 2}$ of PLLA and PLLA $/ 5 \% \mathrm{CaCO}_{3}$ with $T_{c}$.

Compared to neat PLLA, the dates from Table 3 obtained though the Coats-Redfern equation (See Fig. 5) shows that the thermal decomposition activation energy of PLLA $/ 5 \% \mathrm{CaCO}_{3}$ composites is lower than that of PLLA. This result indicates that it could affect the thermal decomposition activation energy of $\mathrm{PLLA} / \mathrm{CaCO}_{3}$ composites and it is possibly affected by the additive $\mathrm{CaCO}_{3}$. This is because the addition of $\mathrm{CaCO}_{3}$ may lead to more defects in the PLLA matrix. However, the thermal decomposition activation energy of PLLA $/ 5 \% \mathrm{CaCO}_{3}$ composites increases with increasing heat treatment temperature.
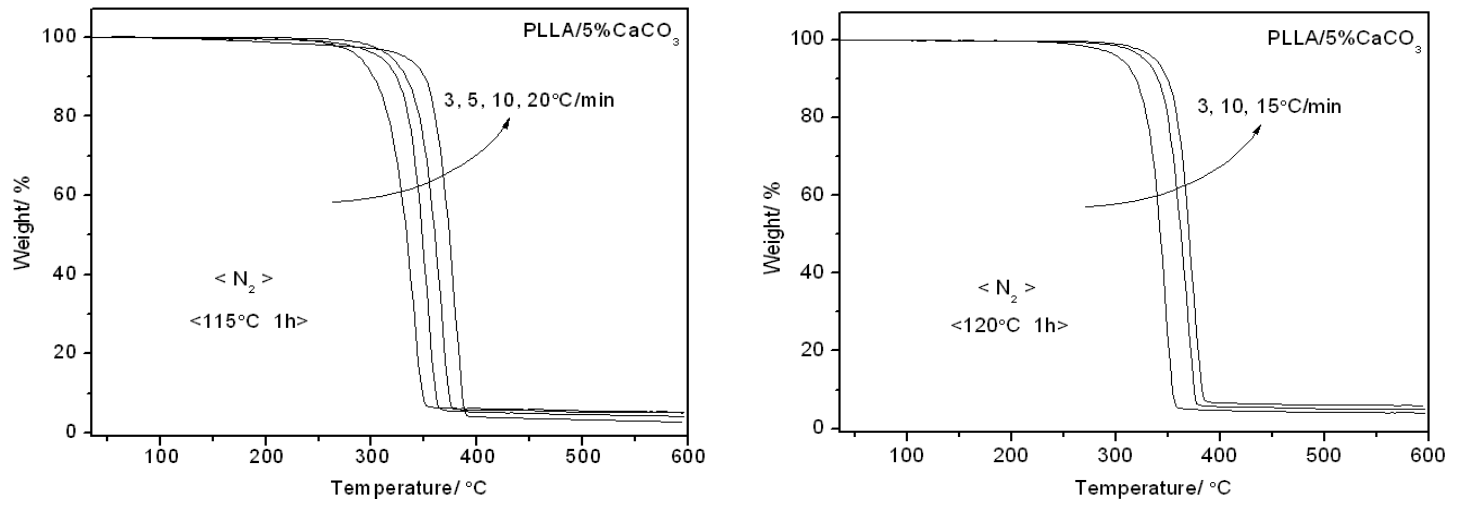

Fig. (4). Thermal decomposition of $\mathrm{PLLA} / 5 \% \mathrm{CaCO}_{3}$ after heat treatment at different temperature for $1 \mathrm{~h}$.
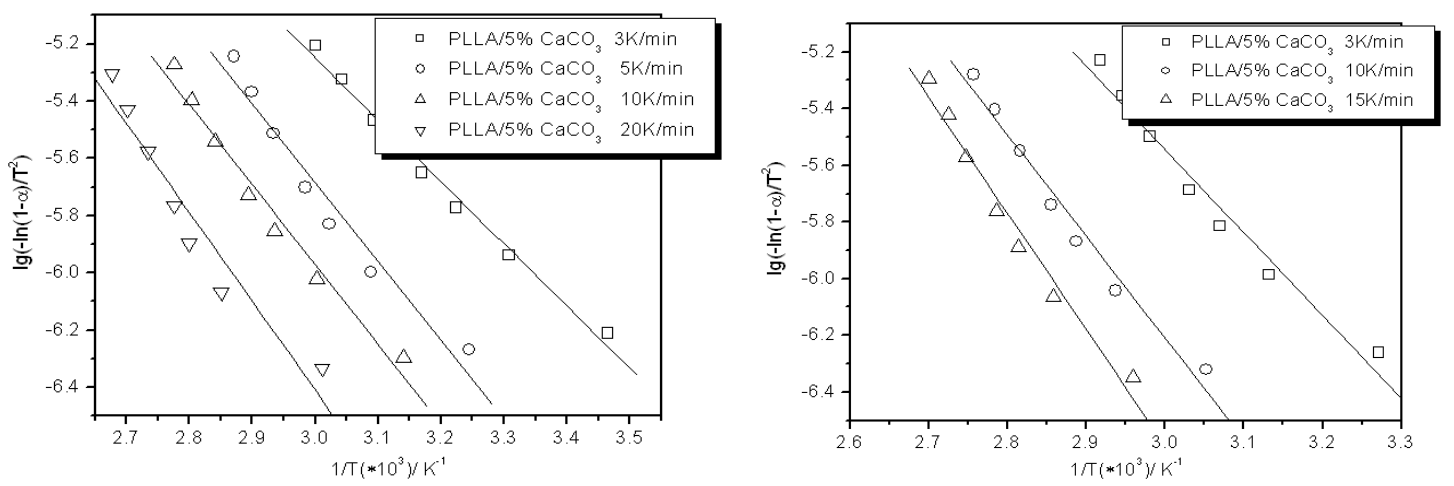

Fig. (5). Coats-Redfern curves of PLLA $/ 5 \% \mathrm{CaCO}_{3}$ composites. 
Table 3. Thermal decomposition kinetics parameters of PLLA/5\% $\% \mathrm{CaCO}_{3}$ composites.

\begin{tabular}{|c|c|c|}
\hline \multirow{3}{*}{ Sample } & $\boldsymbol{\beta}$ & $\mathbf{E}_{\mathbf{a}} / \mathbf{K J} / \mathbf{m o l}$ \\
\hline \hline \multirow{3}{*}{ PLLA $/ 5 \% \mathrm{CaCO}_{3}\left(115^{\circ} \mathrm{C} 1 \mathrm{~h}\right)$} & 3 & 41.514 \\
\cline { 2 - 3 } & 5 & 52.469 \\
\cline { 2 - 3 } & 10 & 53.574 \\
\hline \multirow{3}{*}{ PLLA $/ 5 \% \mathrm{CaCO}_{3}\left(120^{\circ} \mathrm{C} 1 \mathrm{~h}\right)$} & 20 & 59.493 \\
\cline { 2 - 3 } & 3 & 56.137 \\
\cline { 2 - 3 } & 10 & 68.747 \\
\hline
\end{tabular}

\section{CONFLICT OF INTEREST}

The authors confirm that this article content has no conflict of interest.

\section{ACKNOWLEDGEMENTS}

This work was supported by the National Natural Science Foundation of China (project number 51403027), China Postdoctoral Science Foundation (project number 2013M531937), Natural Science Foundation Project of CQ CSTC (project number cstc2012jjA50001), Scientific and Technological Research Program of Chongqing Municipal Education Commission (project number KJ131202).

\section{REFERENCES}

[1] Cai YH. Crystallization and melting behavior of biodegradable poly(L-lactic acid)/talc composites. Eur J Chem 2012; 9(3): 156974.
[2] Yang J-H, Shen Y, He W-D, et al. Synergistic effect of poly(ethylene glycol) and graphene oxides on the crystallization behavior of poly(l-lactide). J Appl Polym Sci 2013; 130(5): 3498508.

[3] Chen H-M, Chen J, Shao L-N, et al. Comparative study of poly(Llactide) nanocomposites with organic montmorillonite and carbon nanotubes. J Polym Sci Part B-Pol Phys 2013; 51(3): 183-96.

[4] Fan YQ, Yu ZY, Cai YH, et al. Crystallization behavior and crystallite morphology controlling of poly(L-lactic acid) by adding $N, N^{\prime}$-Bis(benzoyl) sebacic acid dihydrazide. Polym Int 2013; 62(4): 647-57.

[5] Shih Y-F, Huang C-C. Polylactic acid (PLA)/banana fiber (BF) biodegradable green composites. J Polym Res 2011; 18: 2335-40.

[6] Meng QK, Hetzer M, De Kee D. PLA/clay/wood nanocomposites: nanoclay effects on mechanical and thermal properties. J Compos Mater 2011; 45(10): 1145-58.

[7] Harintharavimal B, Azman H, Mat UW, Yussuf AA, Shamsul BAR. Novel toughened polylactic acid nanocomposite: Mechanical, thermal and morphological properties. Mater Des 2010; 31: 3289-98.

[8] Cai YH, Yin JB, Fan YQ, Yan SF, Chen XS. Crystallization behavior of biodegradable poly(L-lactic acid) filled with a powerful nucleating agent- $N, N^{\prime}$-Bis(benzoyl) suberic acid dihydrazide. J Appl Polym Sci 2011; 121(3): 1408-16.

[9] Coats AW, Redfern JP. Kinetic parameters from thermogravimetric data. Nature 1964; 201: 68-9.

[10] Wang B, Wang Q, Li L. Morphology and properties of highly talcand $\mathrm{CaCO} 3$-filled poly(vinyl alcohol) composites prepared by melt processing. J Appl Polym Sci 2013; 130(5): 3050-7.

[11] Hassan TA, Rangari VK, Jeelani S. Mechanical and thermal properties of bio-based $\mathrm{CaCO}_{3} /$ soybean-based hybrid unsaturated polyester nanocomposites. J Appl Polym Sci 2013; 130(3): 144252 .

[12] Gong L, Yin B, Li L-P, et al. The morphology and mechanical properties of $\mathrm{PP} / \mathrm{EPDM} /$ nano-CaCO3 composites: effect of initial mixing state. Polym Bull 2013; 70(11): 2935-52.

[13] Guo-xiang Z, Zhang X, Bing-jian L, Cai-xia Z, Jin-chun L. Effect of mineral fillers on crystallization and melting behavior of Poly(lactid acid)/mineral filler composites. Acta Polym Sin 2012; 9: 952-7. 